\title{
Women as Paid Domestic Workers
}

\author{
Siddhartha Sarkar \\ Department of Commerce, Dinhata College
}

KEYWORDS Female domestic workers; paid and unpaid domestic work; work and wage of domestic workers

ABSTRACT It is found that among all categories in the informal sector, earnings of domestic servants are lowest and their problems are many. They are being employed generally for household tasks which include washing utensils and clothes, fetching water, sweeping and cleaning house along with a few outdoor tasks like irregular marketing, grocery shopping, ration drawing even childcare activity. In fact, many of these women are looking after more than one household but spend more time and work far more for their employer's than work in their own household.

\section{INTRODUCTION}

It is found that among all categories in the informal sector, earnings of domestic servants are lowest and their problems are many. They are being employed generally for household tasks which include washing utensils and clothes, fetching water, sweeping and cleaning house along with a few outdoor tasks like irregular marketing, grocery shopping, ration drawing even childcare activity. Clearly, one of the main differences between paid and unpaid domestic work is that former involves following a work routine, which is imposed by the employer's order rather than evolved for oneself (Cock, 1989). In fact, many of these women are looking after more than one household but spend more time and work far more for their employer's than work in their own household.

In many studies the focus has been on women's labour participation in agricultural and allied activities often erroneously considered to be only form of paid work available to the women of lower strata. In fact, in many rural areas female labourers work as domestic servant, often combining this employment with agricultural work on a seasonal and even daily wage basis (Kothari, 1991). Hence, domestic work contri-butes a substantive type of employment and generation of earnings for many women.

\section{Objectives}

Over last few decades, there have been a rapid growth in the number of women employed in India with majority of them being engaged in

Address for Correspondence: Siddhartha Sarkar, 250, Pandapara Colony, Jalpaiguri 735 101, West Bengal, India

E-mail: siddhartha_31@yahoo.com informal sector of the economy where jobs are often low paid and repetitive.

As the number of female workers in the informal sector in India has gone up considerably, it implies employment opportunities for them in the formal sector have become restricted. On account of easy availability of low paid labour in the informal sector, there is every possibility of more and more economic activities in this sector. Therefore, an attempt has been made in this study to trace out the problems associated with the process of women participation as well as the manner in which workingwomen's lives in the informal sector in Cooch Behar district of West Bengal are being affected by the process of economic development and social change.

The objectives of the study are to examine the level of women labour participation in domestic services. An effort has been made to reveal the socio-economic conditions of paid domestic workers in the district. It has also been tried to examine the general nature of working conditions of women domestic workers, their special problems and how they combine wage work with domestic responsibilities in the district.

\section{METHODOLOGYANDLIMITATION}

The study of women at work in the informal sector with special reference to female domestic workers in Cooch Behar district of West Bengal is an empirical one. The study is based on survey research technique. The various informations on 200 sample female domestic workers in the informal sector have been gathered from extensive survey of field investigation. Since working women in informal sector of Cooch Behar district constitutes a heterogeneous group, stratified sampling method has been undertaken while collecting the sample workers. 
This study, however, is not free from its limitations. The data is based on the respondents estimate and memory recall. Since most of the women workers in informal sector are illiterate, their inability to provide precise information put in trouble in generalizing the case. Some respondents were unwilling to disclose their exact earning and they had no idea regarding their expenditure patterns. These limitations may have affected the survey result to some extent. Despite these limitations, the researcher has taken utmost care in analyzing the problems.

\section{PAIID VS. UNPAID DOMESTIC WORKS}

Two types of domestic work can be found in practice namely, paid domestic work and unpaid domestic work. While a maid is employed for doing sundry household tasks on the basis of agreed wage payment, the daily activities performed by the maid in the respective employer's household may be termed as paid domestic work. On the other hand, the time spent by a male or female folk in different activities of own household may be termed as unpaid domestic work. Paid household work is always visible, but unpaid one is often invisible.

A United Nations (1991) report on women's work patterns based on surveys made across countries of the world gives a summary of women's devotion of time to both paid and unpaid economic activity. The findings are as under:

i) Women spend more of their time working than men folk in all developed and developing regions except northern America and Australia where the working hours are almost equal.

ii) In developing countries, women spend more time in the labour force than their household work. Men, by contrast, are spending less amount of time working in the labour force than before in all developed regions and slightly increasing amounts of time in housework in northern America, Australia and Western Europe.

iii) In Africa, Asia and the Pacific, women work as on average 12 - 13 hours more than men per week.

iv) Men in developing regions generally do less household chores than men in the developed regions.

v) Women everywhere in the world have nearly total responsibility for housework.
While men 'help out' women retain the responsibility of housework.

Since the unpaid domestic workers do not manage all household tasks, often they have to employ an additional paid domestic worker in their household. The demand for or dependency on paid domestic maids among middle class families is on the rise because of the following reasons:

i) Men spend very little time on their daily indoor household activities and a slow increase in household work by men (Juster 1985, Ramu 1987, Spitze 1988, Thompson and Walker 1989). Hence, it becomes impossible to do all necessary household tasks by an unpaid female folk.

ii) While woman of a household is employed, her husband does not show any substantial increase in the amount of family work they do (Kammaeyer 1987). Obviously, dependency on paid domestic workers increases.

\section{PROBLEMS FACED BY DOMESTIC WORKERS AT WORK PLACE}

The general problems faced by the female domestic servants at work place are as under:

i) The domestic workers are not satisfied with their present wages and they expect more. It is true that the wage levels of domestic maids are much less than not only what they need, but also lower than their male counterparts who often do almost comparable type of work.

ii) The workers often express their grievances for imposing extra work burden by the employers while guests come. The extra money for that additional work is not sufficient. A lump sum amount is paid for extra work. Often, the employer does not pay anything.

iii) Few employers have a tendency to deduct wage for absence in work.

iv) The employers do not permit any extra leave. As a result, they have to attend work regularly leaving any urgent personal necessity.

v) Many workers face sexual harassment by their male employers. Verbal sexual harassment by the male employers is some thing that is generally very common. This is one of those problems at work place that only women face and it is probably one of the few problems that may be perpetuated by male employer. 
vi) Most of the workers being less educated, the awareness to form a union is lacking among them. As there is no such domestic servants' unions formed across the country, they cannot raise their voice against employers' negative attitude.

vii) The real wages in the form of food, cloth etc. are not sufficient. Sometimes quality of food provided by the employer is inferior.

viii) Often nature of work may vary from one day to another or volume of work rises day by day in the employers' house. Then the workers have to do all tasks with initial agreed wages. The employers do not offer any extra wages for increasing workload. On the other hand, workers do not protest because of getting fired.

ix) So far as the annual increment of wages is concerned, a few domestic workers enjoy the benefit.

\section{WORKANDWAGEOFDOMESTICWORKERS}

More or less all middle and upper class people employ preferably female domestic servant in their households. The female domestic workers can be categorized as thika ${ }^{1}$ workers, full time workers and residential workers. The thika workers serve for 3-4 hours a day in a household. They work in 2-3 houses daily. However, number of households to be served by thika workers largely depends on their efficiency and capability to work. On the other hand, the full time workers serve in a single household for maximum duration of $8-10$ hours daily which includes a part of idle time. The employers normally provide them one time meal. Often, thika workers demand for one time meal while there is a heavy workload. The residential workers stay at employer's house and they are provided two time meal. The residential workers do all works of the employer's household. Apart from these three types of domestic maids, another type of domestic worker may be found. They are part time 'occasional or emergency' workers who serve for a few days on a purely temporary basis when any emergency arises in a household. They generally work in the present employer's neighbour's household for a very short duration.

The tasks performed by all types of domestic workers are almost same. They perform a bunch of work such as cleaning utensils, sweeping and cleaning rooms, washing clothes, fetching water etc. The cooking is generally delegated to the efficient workers. This skilled task is not assigned to lower class workers, because higher caste employers do not allow schedule caste or schedule tribe women to enter their kitchen. However, caste is not a matter for other household tasks. More over, some allied tasks are to be carried out by the domestic maids namely, minding little children, daily marketing, looking after house etc., but their number is small.

Therefore, the activities performed by paid domestic workers are similar to those carried out within their own household, although specific tasks and ways of carrying them out may vary.

One domestic maid described her workday as under:

I come to Bowdi's house at 7 a.m daily. While I reach at Bowdi's house, she gives me a cup of tea and biscuit. Then I go to fetch water from nearby drinking water tap. The containers are heavy and often I have to make double trip. I can meet my friends at the tap and we interact until our return. Every day I have to stand in a long queue for fetching water. Sometimes Bowdi shouts at me do not waste so much time at tap, there is a lot of sundry work to do. After getting back from tap I have to assist Bowdi regarding breakfast and food preparation, because Dada goes to office at 10 a.m. Then I clean house and wash clothes. I have to wash 6-10 clothes daily. Then I clean bathroom. After they have eaten, I wash dishes and utensils. In most of the days, I do no eat there. I go home at 12 noon with my food and cook for my family. I again come back at 3 p.m and again go to fetch water. After washing utensils and sweeping the rooms, I watch movie on the television at Bowdi's house. I go back my house at 5 p.m. On my way home, I collect firewood. I earn Rs. 300 per month, but the amount is insufficient for the survival of my family.

One domestic worker complained:

I have to wake up early in the morning to prepare food for my family. I leave my children unfed so that I can arrive at doctor's house to wash and dress his children.

Most of the domestic maids carry out all domestic tasks except cooking. It is generally thought that cooking involves some skill and expertise, moreover being a time consuming process, therefore can not be done efficiently by a domestic servant. In lieu of cooking in the employer's household, they can serve in more than two households at a time. 
Domestic workers are often to do tasks for other members of their employers' guests, particularly during special occasions. During this time, domestic workers can carry out necessary preparations together with other workers. Although, this involves a lot of work but many workers enjoy the change from daily monotonous routine work that they are to perform and it is one of the few occasions while they can work together. However, one woman described the problems faced at such time:

I had to work for the whole day a week because of Didi's wedding. All they gave me was little extra money and a sari. My children came with me, but they were simply neglected. The employer's extra money does not help with all that work.

Domestic workers carry out other tasks, which are not linked with domestic workers. Domestic maids are often sent as messenger from one woman to another. While for example, a neighbouring household requires a maid, the employers of the household already having worker sends her domestic servant to persuade her fellow friend to work for other. This role as messenger provides the workers with a degree of power as the employer may depend on her for additional need of worker in future.

Since domestic workers are required to work extra hours, they become unable to maintain their own domestic responsibilities. As a result, their husbands and other household members ask for negotiation against extra demand of the employers. The worker(s) addressed:

The employers want us to work more particularly during special occasions, but our husbands get angry. One day my employer wanted me to stay and work in the evening. Initially, I did not agree because I am to cook for my family. I required money for my child's education, so I did the work. Sometimes my husband gets angry because of serving extra hours for the employers. While I work overtime, then I do not have enough hours for looking after my own household.

Thus, domestic workers have to combine different types of work in order to survive and must organize their time with a view to meeting all duties properly.

So far as the wage is concerned, it is based on the nature of work, number of members in employer's household, size of the house or number of rooms, time to be spent etc. Wages paid for performing allied activities is generally higher than usual household work. Among all types of domestic workers, thika servant is paid least. The residential workers get more wages in cash in addition to their daily real wages than a thika maid. The wages of full time and residential workers do not differ so, but latter enjoy more real wages than former. Besides, part time occasional or emergency workers always expect high wage from the employers and their total earnings at the end of the part time job become lucrative as compared to their average earnings. Apart from the cash wages, domestic maids received new clothes and festival grant in cash.

The wages of domestic servants may vary from one region to another. It is found that rate of wages in semi urban areas are comparatively lower than urban areas. This is because, supply of domestic servants in semi urban areas is often more than their demand and sometimes workers belonging to semi urban areas have no bargaining capacity. However, still the wages of domestic servants are low in comparison with other workers in the informal sector.

\section{SURVEY FINDINGS}

The field survey on 200 female domestic workers randomly selected from 200 households of Cooch Behar and Dinhata. The following is the general findings of the survey.

It is surprising to note that few of the domestic servants immigrated from Bangladesh. Although the reported percentage was not significant, but their number is on the rise. The number of native domestic workers was 183. Therefore, domestic servants and maids have tended to focus on the international migration of women labourers.

The general educational standard of the female domestic servants was very low. It has been observed that $89 \%$ of the workers were illiterate. Only $11 \%$ of the workers had schooling experience. Out of $11 \%, 9.5 \%$ had primary education and $1.5 \%$ had education beyond the primary level. Only one woman had passed class VIII standard.

The nature of employment of all domestic servants did not identical. Someone preferred to work as thika maid, but other might like to serve as residential or full time worker. It is found that majority of the domestic workers preferred to work as thika servants on the assumption of more earnings. It has been found that $81 \%$ of the workers served as thika labour, while $6 \%$ of the 
workers stayed in the employers' households. Thika and full time domestic maids lived in nearby locality, but most of the residential maids migrated from other districts or villages. Out of 12 residential maids, 7 were from different regions of North Bengal. A good number of employers preferred to employ adolescent maids, because they could easily be directed and motivated for household work. Their probability to leave the employer's household was also minimal.

The recruitment of the domestic workers may be done either through employers' own effort or through workers' own effort. Sometimes, would be employers' neighbour's effort as well as fellow workers' effort play a vital role in recruitment of domestic workers. In fact, direct recruitment through employers' own effort constituted $36.5 \%$. It is observed that as far as the recruitment of domestic maids was concerned workers' own effort and their fellows' effort constituted $49 \%$. While would be employers' neighbour's effort was only $14.5 \%$. Generally part time maids were employed with the help of neighbour.

Two types of domestic maids can be identified from the survey. One group of workers was not breadwinners of their family, but willing to serve as domestic servants for income supplementation. On the other hand, most of the domestic maids were working to earn their livelihood.

The first group of workers started working mainly after giving birth of first child. According to them, they preferred and enjoyed the work. But most of the respondents were forced to do this job to feed their family. According to them, there was no alternative way to earn money with such a little education.

Economic compulsion was the main reason behind taking the job as domestic maids (91.5\%). $5.5 \%$ of the workers reported that they had chosen the job for supporting their husband. A few percent of workers served for independent income (3\%). There was no worker in the findings who worked for passing out idle time.

A majority percentage of workers had to travel on foot to reach at work place $(78.72 \%) .14 .36 \%$ of domestic maids reported that they availed their husband's rickshaw ${ }^{2}$ to arrive at work place. Only $6.92 \%$ of the workers used other mode of transpiration like bus or train.

The workers had to serve for their own household also. The thika and full time maids had to simultaneously manage their own family. The table 1 shows the level of participation of domestic maids in own household work.

It is found that apart from the employer' sundry household works, maids had to do a lot of tasks for their own family. The domestic servants had nearly total responsibility for own housework. It is also noticed that their husbands spent a little time on the large bulk of daily indoor activities like washing clothes and utensils, water collection and cooking. Hence, majority of the household work was to be carried out by the maid herself.

It is rational that maids should get refreshment like tea, bread etc. and minimum one time food at work place irrespective of their nature of work. Among the respondent workers, 50.5\% enjoyed refreshment only and $36.5 \%$ got food either once or twice a day depending upon their nature of employment. $13 \%$ of the workers did not get any type of refreshment and food at work place.

The domestic servants had grievances against the employers. $18 \%$ of the workers reported that they were considered as chakrani ${ }^{3}$ in the employers' households. However, many employers treated their domestic maids as a family member $(65.5 \%)$. A few employers also commanded excessively over the workers $(5 \%)$. Besides, the maids faced other type of gender specific forms of discrimination and oppressions at their work place. A severe problem women workers faced was that of sexual harassment by the male employers (11.5\%).

The extent of trustworthiness of employers was not always satisfactory. $51 \%$ of the maids reported that their employers trusted on them

Table 1: Level of participation in own household task by domestic workers

\begin{tabular}{lrrrrr}
\hline Household Tasks & \multicolumn{2}{c}{ Self } & Husband/Other Members & Jointly \\
\hline Washing clothes and utensils & 176 & $(93.62)$ & $02(1.06)$ & $10(5.32)$ \\
Water collection & 185 & $(98.40)$ & $01(0.54)$ & $02(1.06)$ \\
Fuel collection & 105 & $(55.85)$ & $60(31.91)$ & $23(12.24)$ \\
Food preparation & $188(100.00)$ & $0(0)$ & 0 & $(0)$ \\
Maintenance of house & $57(30.32)$ & $08(37.77)$ & $60(31.91)$ \\
Childcare & 176 & $(93.62)$ & $(4.26)$ & $04(2.12)$ \\
\hline
\end{tabular}

Figures in the parentheses are percentages.

Only thika and full time workers were considered. 
moderately. The high trustworthiness among the employers was only $4.5 \%$. Some employers had no trustworthiness at all $(6 \%)$.

Sometimes the workers had to participate in doing allied activities in the employer's household. These were in addition to the regular household tasks. Daily marketing, ration drawing, childcare activities etc. were often found to be performed by the domestic maids where in general husband and wife both were employed. The percentage of the workers involved in such activities is 16.5. The workers complained that they had not been paid enough for doing these allied tasks. Often they had been provided a lump sum amount at the end of every month. Instead of doing such activities, they preferred to earn by serving another households. They did not really like such activities. This is why $83.5 \%$ of the workers did not take participation in such activities.

The number of the household to be served by the workers largely depends on the physical capability of the individual servant. It is found that young adults served in more than two households at a time (52\%), while old aged maids served in a single household. The middle aged maids preferred to work as thika worker and old ones like to serve as full time maid. It is found that $13 \%$ of the workers served in more than three households daily.

Very often the contribution that a female servant makes to the family determines her status in the household. The earnings of the workers are considered to be right fully at disposal of the household. But there is no or a very little concept of women's autonomy to control over their own earnings. It has been found that most of the female domestic servants contributed to their household in the range of Rs. 200 and Rs. 300 per month $(82 \%) .5 .5 \%$ of the respondents had a contribution of Rs. 300 to Rs. 400 , while $3 \%$ of them did not contribute at all.

Few workers were very much concerned about the potentiality of savings. They saved a part of their earnings either at post office or at home. It is interestingly found that a few employers convinced the workers to go for saving. A few maids deposited a certain amount in the post office every month thinking for the future $(2.0 \%)$. However, majority of the workers had no any saving potentiality $(86.5 \%)$ although they were eager to save, but a limited fund did not permit.

Table 2 shows daily work profile of female domestic maids of various age groups. The table is arranged taking into account of average activities performed by them. Column 2 reveals activities of an adolescent girl. Column 3 shows activities of a maid in middle age group and column 4 discloses a day of a woman in the old age group. The daily tight schedule of the domestic servants has been presented in table 2 .

\section{CONCLUDING REMARKS AND SUGGESTIONS}

The demand for women domestic servants

Table 2: Daily work profile of female domestic workers

\begin{tabular}{|c|c|c|c|}
\hline Time & Young age group & Middle age group & Old age group \\
\hline 5.00 a.m & - & Rises & Rises \\
\hline 5.30 a.m & - & Fetches water and cleans own house & Fetches water for family \\
\hline 6.00 a.m & Rises & Feeds children & Prepares breakfast for family \\
\hline 6.30 a.m & Takes breakfast & Prepares breakfast for family & $\begin{array}{l}\text { Attends work place- } 1 \text { and takes } \\
\text { breakfast. }\end{array}$ \\
\hline 7.00 a.m & $\begin{array}{l}\text { Goes to work place and } \\
\text { does domestic tasks }\end{array}$ & $\begin{array}{l}\text { Goes to work place-1 and washes uten- } \\
\text { sils, clothes, cleans rooms }\end{array}$ & Does domestic work at work place \\
\hline 8.00 a.m & $\begin{array}{l}\text { Helps in cooking at work } \\
\text { place }\end{array}$ & Takes breakfast at work place & Prepares food at work place \\
\hline 10.00 a.m & $\begin{array}{l}\text { Does other work at work } \\
\text { place }\end{array}$ & Goes to work place-2 and does work & $\begin{array}{l}\text { Goes to work place-2 and } \\
\text { prepares food }\end{array}$ \\
\hline 12.00 noon & Returns home & Attends work place-3 and does work & Returns home \\
\hline 1.30 p.m & Helps mother at home & Returns home and cook for the family & Takes rest \\
\hline 2.30 p.m & Takes food at work place & Takes rest & Takes food at work place \\
\hline 3.30 p.m & $\begin{array}{l}\text { Washes utensils and } \\
\text { sweeps rooms }\end{array}$ & Washes utensils and sweeps rooms & Returns home \\
\hline 5.00 p.m & Returns home & Returns home and washes clothes & Interacts with neighbour \\
\hline 7.00 p.m & Helps mother at home & Prepares food and feeds the children & Takes food Goes to bed \\
\hline 8.00 p.m & Takes food & Takes food & - \\
\hline 9.00 p.m & Goes to bed & Goes to bed & - \\
\hline
\end{tabular}


among middle and upper strata people in the Cooch Behar district is generally fulfilled from native women and often domestic service contributes a substantive form of employment and generation of earnings for many poor women in the district.

The domestic tasks can be classified as paid domestic work and unpaid domestic work. The paid domestic workers generally perform a series of household tasks such as cleaning utensils, sweeping and cleaning rooms, washing clothes, fetching water etc. However, the cooking is assigned to the expert workers. The wages of the female domestic workers are very low compared to other workers in the informal sector. The domestic servants enjoy both money wages as well as real wages.

The female domestic servants have to face a lot of problems at the work place which include low level of wage, a minimal pay or no pay for extra work, absence of leave facility, sexual harassment by male employer etc. These problems can never be overcome until the concept of unionism is developed among the female domestic workers.

The economic compulsion is the main hardship for taking the job as domestic servants. The general educational status of the female domestic workers in the district is not satisfactory. The workers contribute a lion part of their earnings to the family and few of them have saving potentials too. Since wages of the female domestic servants are very low, they have been worst exploited.

The female domestic workers are subject to variety of exploitations starting from low wages to maltreatment and sexual harassment by the employer. However, with a view to improving the working conditions of female domestic workers the following suggestions are recommended:

First, fixing wages to keep pace with other paid work in the informal sector.

Secondly, providing support service like day meal to all domestic workers irrespective of their nature of work.

Thirdly, providing the workers some degree of flexibility in working hours.

Fourthly, minimizing degree of command over the workers by the employers and imposing acceptable workload to the workers.

Fifthly, building up proper understanding between workers and employers over worker's failure to attend at work.

Sixthly, setting up formal domestic workers unions, which can look after their interests.

Seventhly, providing equitable extra wages for extra workload due to arrival of employer's guests on holidays and festivals.

Eighthly, providing annual incremental benefit to all workers.

Ninthly, providing minimum leave facilities to the workers.

Lastly, passing out legislations for the welfare of the workers.

\section{NOTES}

1. Thika is used to denote piece rate.

2. A three-wheel cart driven by human being.

3. A derogatory local term to indicate the maidservant.

\section{REFERENCES}

Cock, J .1989. Maids and Madams: Domestic Workers under Apartheid. London: The Women's Press.

Juster, F.T .1985. "Investments of Time by Men and Women", in F.T. Juster and F. P. Stafford (eds.), Time, Goods and Well-being. University of Michigan, Survey Research Centre.

Kammaeyer, K. C. W. 1987. Marriage and Family: A Foundation of Personal Decisions. New York: Allyn and Bacon.

Kothari, U. 1991. Women's Work and Rural Transformation in India. Unpublished Ph. D. Thesis, University of Edinburgh.

Ramu, G. N .1987. "Indian Husbands: Their Role Perceptions and Performance in Single and Dual Earner Families". Journal of Marriage and the Family, 49: 903-915.

Spitz, G .1998. "Women's Employment and Family Relations: A Review". Journal of Marriage and the Family, 50: 595-618.

Thomson, L. and A.J. Walker. 1989. "Gender in Families: Women and Men in Marriage, Work and Parenthood". Journal of Marriage and the Family, 51: $845-871$

United Nations. 1991. The World's Women 1970-1990. New York: UN. 